\title{
BMJ Open Conducting focus groups in neurodegenerative disease populations: ethical and methodological considerations
}

\author{
Annabel Jones, ${ }^{1}$ Philippa Morgan-Jones, ${ }^{2}$ Monica Busse (D) , ${ }^{3}$ \\ Victoria Shepherd (i) , Fiona Wood (i) ${ }^{4}$
}

To cite: Jones A, MorganJones P, Busse M, et al. Conducting focus groups in neurodegenerative disease populations: ethical and methodological considerations. BMJ Open 2021;11:e041869. doi:10.1136/ bmjopen-2020-041869

- Prepublication history for this paper is available online. To view these files, please visit the journal online (http://dx.doi. org/10.1136/bmjopen-2020041869).

Received 19 June 2020 Revised 07 December 2020 Accepted 14 December 2020

\section{(D) Check for updates}

(C) Author(s) (or their employer(s)) 2021. Re-use permitted under CC BY-NC. No commercial re-use. See rights and permissions. Published by BMJ.

${ }^{1}$ School of Medicine, Cardiff University, Cardiff, UK

${ }^{2}$ School of Engineering, Cardiff University, Cardiff, UK

${ }^{3}$ Centre for Trials Research, Cardiff University, Cardiff, UK

${ }^{4}$ Division of Population Medicine and PRIME Centre Wales, Cardiff University, Cardiff, UK

Correspondence to Professor Fiona Wood; wood@cardiff.ac.uk

\begin{abstract}
Background Involvement of vulnerable populations in research is critical to inform the generalisability of evidence-based medicine to all groups of the population. Objective In this communication, we reflect on our previous research, and that of other authors, to identify and explore key ethical and methodological considerations. Discussion Focus groups are a widely implemented qualitative methodology, but their use, particularly in vulnerable neurodegenerative disease populations, is not straightforward. Although the risk of harm is generally low in focus group research, neurodegenerative disease populations are particularly vulnerable to issues relating to comprehension and their capacity to consent. Physical and cognitive impairments may also affect social interactions among participants and therefore impact data collection and analyses.

Conclusion We offer a number of ethical and methodological recommendations to facilitate the processes of recruitment and data collection when conducting focus groups with neurodegenerative disease populations.
\end{abstract}

\section{BACKGROUND}

Vulnerable populations have specific healthcare needs and are therefore frequently the focus of research. Examples of vulnerable populations are patient groups with chronic or terminal illness, older people and young children, and those without capacity. Those diagnosed with a neurodegenerative disease may also be deemed as vulnerable. Neurodegenerative disease is an umbrella term used to describe any disease that affects the nervous system due to specific neuronal degeneration or inflammation, the main features of which are described in table 1.

Symptoms of these conditions can result in disruptions to patients' activities and interests. Research participation is no exception to this, with patients and caregivers reporting their impairments to be a significant barrier to collaborating in research. ${ }^{1}$ A paternalistic desire to protect vulnerable populations and subsequently exclude them from research has led to subsequent 'evidence-biased' care. ${ }^{2}$ Lack of inclusion can also be viewed as discriminatory. ${ }^{3}$ While it can be challenging to involve patients with these symptoms, ${ }^{4}$ it is clear that meaningful, and critical, contributions to research can still be made. ${ }^{3}$

The aim of this communication is to identify the key ethical and methodological issues researchers face when conducting focus groups in a range of neurodegenerative populations. In doing so, we draw on the authors' personal fieldwork experiences of conducting focus groups among patients with Huntington's disease (HD) and multiple sclerosis (MS). A scoping review was also conducted in order to identify additional literature on conducting focus groups in a broader neurodegenerative population. This communication explores the challenges of conducting focus group research in these populations in terms of recruitment and data collection. Potential solutions are then offered.

\section{THE CHALLENGES}

Challenges of recruitment: the consent process

Capacity, comprehension and voluntariness are essential components of informed consent. ${ }^{5}$ Informed consent is a pivotal part of research ethics and serves to protect the autonomy and right to self-determination of research participants. For informed consent to be valid, the participant must have decisionmaking capacity, which requires them to understand information given to them, retain the information long enough to process the decision, weigh-up the information and communicate their decision. Cognitive and behavioural changes are well documented in neurodegenerative disease and are associated 
Table 1 Neurodegenerative diseases cited in this communication and their main features

\begin{tabular}{|c|c|}
\hline $\begin{array}{l}\text { Neurodegenerative } \\
\text { disease }\end{array}$ & Cardinal features \\
\hline $\begin{array}{l}\text { Huntington's disease } \\
\text { (HD) }\end{array}$ & Autosomal dominant disorder. Core manifestations include chorea, dementia and personality changes. \\
\hline $\begin{array}{l}\text { Parkinson's disease } \\
\text { (PD) }\end{array}$ & $\begin{array}{l}\text { Gradual onset, progressive degenerative disease. Cardinal manifestations include bradykinesia, } \\
\text { tremor, rigidity or postural instability. Non-motor manifestations include autonomic dysfunction and } \\
\text { neuropsychiatric features. }\end{array}$ \\
\hline $\begin{array}{l}\text { Motor neuron disease } \\
\text { (MND) }\end{array}$ & $\begin{array}{l}\text { Degeneration of upper or lower motor neurons leads to varying patterns of signs and symptoms. } \\
\text { These include atrophy, weakness, fasciculations (muscle twitch), spasticity, hyperflexia/hyporeflexia } \\
\text { and hypotonia. }\end{array}$ \\
\hline Alzheimer's disease & $\begin{array}{l}\text { Most common form of dementia. A steady decline in cognitive functioning, with impairments in other } \\
\text { areas such as executive function, language, social cognition and judgement. Accompanied by mental } \\
\text { and behavioural symptoms such as depression, apathy, irritability, aggression and confusion. }\end{array}$ \\
\hline
\end{tabular}

with a decline in capacity. Decision-making capacity must be taken into account when obtaining consent, while also recognising it may change over time. ${ }^{6}$ However, researchers should not make assumptions about a potential participant's inability to consent purely based on disease status, rather they should be assumed to have decisional capacity unless it is established they do not once all practicable steps to support comprehension and decision making have been taken. ${ }^{6}$

In our research to develop a complex intervention to help slow functional decline in HD, we recruited participants from across the spectrum of HD, from prodromal to late-stage disease, in order to attain a diverse range of perspectives ${ }^{7}$ However, we were acutely aware of the cognitive, behavioural and emotional impairments experienced by patients with $\mathrm{HD}$ and their potential to impact on their perceived ability to provide informed consent or willingness to join in a group discussion. Across a range of neurodegenerative diseases, including HD, cognitive impairment affects concentration and the acquisition and storage of new information. This poses challenges for researchers who are required to obtain informed consent prior to any involvement in research. The 2005 Mental Capacity Act governs incapacitated adults' involvement in research in England and Wales that is not a clinical trial of a medicinal product. ${ }^{6}$ This framework supports the inclusion of adults who are unable to provide consent for themselves through enabling responsible consultees (typically family members) to make decisions regarding participation on behalf of the vulnerable person. Our research has found that this responsibility may lead to exclusion of participants who would have otherwise made invaluable contributions. ${ }^{8}$ Focus group research remains a valuable method as they have been found to enable participants with dementia to express their needs and preferences, despite not having capacity as judged by clinical thresholds. ${ }^{3}$

Focus group methodology is advantageous in being a quick and convenient way to collect data. Consent to participate is usually obtained immediately prior to the focus group and so researchers can be reassured that capacity is unlikely to change in the short time elapsed between consenting and participating in the focus group, although consent is always revocable. The feasibility of withdrawing consent during a focus group is, however, up for debate. Having to withdraw in a public manner that may disturb discussion is likely to dissuade participants from doing so. ${ }^{9}$

\section{Challenges for data collection: communication}

Although focus groups are rooted within a constructivist paradigm, with conversational flow integral to the collection of rich data, in reality, there are limitations to how far participants can digress from the topic of interest. In HD, cognition and language are highly related, and patients show deficits in discourse comprehension, understanding implicit information and making inferences. Patients also demonstrate decreased communicative initiative and significant word-finding problems. In our focus group fieldwork with both patients with HD and MS, we noted that problems in communication led to social isolation. ${ }^{710}$ Participants with attention-related deficits related to cognitive decline can delay the progress of a focus group, potentially causing frustration for other participants and affecting the overall quality of data. Short-term and long-term memory deficits may lead to participants forgetting questions, confusing information or retrieving information. ${ }^{11}$ Bradyphrenia (slow processing of information), seen in both $\mathrm{HD}$ and $\mathrm{PD}$, hinders conversation. Dysphasia and word-finding difficulties, seen in a number of neurodegenerative diseases, also impact on communication.

A lessened ability to articulate oneself can exacerbate common behavioural changes such as irritability or aggression. ${ }^{11}$ Behavioural changes from apathy to disinhibition are a core manifestation of some neurodegenerative diseases and only recently has a social cognitive deficit been acknowledged to underlie a range of these so-called 
'problem behaviours'. ${ }^{12}$ It is difficult for researchers to predict and control how the focus group will be experienced by individual participants. ${ }^{13}$ Even though focus groups are more regulated than most everyday conversational encounters, no information sheet and consent form can detail all potential occurrences. While the risk of harm is low compared with other research methods, a duty to safeguard participants remains. Depression, apathy or even aggression, although rare, can cause distress and cause study-specific conversations to deteriorate. Some participants may speak out of turn or disclose views that distress others, potentially leaving others uncomfortable and reluctant to contribute. ${ }^{11}$

\section{Challenges for data collection: motor impairment and fatigue}

The visibility and unpredictability of motor symptoms such as hyperkinesia, instability, tremor and freezing have been found to be a significant barrier to participation in focus groups for patients with movement disorders, particularly those with HD and PD. ${ }^{1}$ As a result of these symptoms, research participants report feeling 'exposed' during social interaction. ${ }^{1}$ These concerns are shared by HD patients with significant chorea (abnormal involuntary movement) and can be exacerbated by being in unfamiliar environments. Researchers have encountered situations where participants have knocked the table or digital recording device, disturbing audio-recordings that can then further impact on the quality of transcriptions and data analysis. ${ }^{11}$

Choreic (involuntary) and dyskinetic (unpredictable) movement may also affect participants' abilities to form social relationships, and therefore engage in meaningful discussion. Conversely, hypokinetic states (loss of movement), a feature of both HD and PD, also impact on the ability to form relationships in social groups. Bradykinesia and a lack of facial expression can be as inhibitory as hyperkinetic movement. In MS, muscle spasms can be uncomfortable, unpredictable and exacerbates fatigue. This fatigue is typically thought to worsen as the day progresses. ${ }^{14}$ Similarly, progressive muscle wasting contributes towards significant use-dependent muscular fatigue in MND.

\section{SOME ETHICAL AND METHODOLOGICAL RECOMMENDATIONS}

Methods to improve the process of recruitment could include opportunities that allow participants to visualise questions that plan to be discussed prior to the focus group. Short 'preinterviews' could also allow researchers to assess eligibility for participation, while still regarding comprehension and consent as an ongoing process. ${ }^{15}$ Making information more accessible to participants prior to obtaining consent has also been found to be key to maximising participant comprehension. ${ }^{16}$ These suggestions are shared by the Mental Capacity Act's Code of Practice, which recommends the use of simple language and imagery, such as pictures or diagrams, to improve the accessibility of information to those with reduced comprehension. ${ }^{6}$ Despite this, many researchers are still failing to make adequate adaptations to their information sheets and consent forms. ${ }^{17}$ Another approach would be to monitor consent throughout the focus group study. This form of 'process consent' is more sensitive to the issues that may arise when including vulnerable patients in qualitative research. ${ }^{17}$

To address bradyphrenia, memory problems or speech impairment, limiting the number of questions or restructuring tasks within a focus group could open more time for discussion. In our fieldwork, including caregivers was deemed a necessity to facilitate the inclusion of patients with late-stage HD and ameliorate diminished comprehension and communicative abilities. We therefore recommend inviting relatives or staff members involved in participants' care to attend alongside patient participants. In our focus groups, the presence of caregivers alleviated communicative and cognitive deficits, both in the recruitment process and during data collection; thus, their presence appeared to support participant comprehension and subsequent decision making. ${ }^{7} 10$ Involving caregivers also demonstrates the value given to the carer-patient relationship and allows carers to redirect the person they are supporting, clarify statements or even help them delve deeper into questions, although their input may influence patient participants' opinions. In our focus groups, healthcare professionals and HD association volunteers, known to some participants, were involved in recruitment and data collection, with the hope of creating a more collaborative environment. ${ }^{7}$ However, efforts were made to prevent caregivers from overpowering vulnerable group members. For example, moderators ensured that statements made by caregivers were acknowledged by the appropriate patient, for verbal or non-verbal agreement.

As we invited people across the spectrum of disease for our MS and HD studies, we were aware that participants may become upset by seeing other patients at later disease stages. To minimise this discomfort, we encouraged participants to sit where they wished and chat to other participants before the focus group formally began. We noted that this natural group formation helped participants to become comfortable with one another, with group dynamics already beginning to establish. ${ }^{7}$ Thordardottir also employed a strategy to create homogeneity within focus groups with patients with PD by grouping participants into mild, moderate and severe groups based on self-reported disease severity. ${ }^{1}$ Focus group size was also limited. For focus groups containing frail or vulnerable individuals, six is the maximum recommendation, ${ }^{17}$ and we have included a maximum of six in our focus groups. $^{710}$

In order to compensate for physical and cognitive impairment, the structure and timings of focus groups should be flexible. We conducted our focus groups earlier in the day (but not too early) at time where physical and cognitive fatigue is minimal. ${ }^{10}$ If exhaustion or irritability arises, it may be suitable to pause the focus group and 
Table 2 Impairments caused by neurodegenerative disease and possible implications for focus group participation

\begin{tabular}{|c|c|c|}
\hline Potential impairment & Possible issues & Our recommendations \\
\hline $\begin{array}{l}\text { Impaired motor function (gross } \\
\text { and fine) }\end{array}$ & $\begin{array}{l}\text { Accessibility issues due to impaired } \\
\text { mobility. May be unable to sign for } \\
\text { written consent. }\end{array}$ & $\begin{array}{l}\text { Ensure focus group venues have disabled access. } \\
\text { If possible, hold in a familiar environment. Explore } \\
\text { alternative options for written consent. }\end{array}$ \\
\hline Involuntary movement & $\begin{array}{l}\text { Difficulty reading and holding items. May } \\
\text { be exacerbated by stress and having to } \\
\text { sit for prolonged periods. May distract } \\
\text { other focus group members. }\end{array}$ & $\begin{array}{l}\text { Consider homogeneity in disease stage when } \\
\text { recruiting participants. Informal atmosphere } \\
\text { to minimise stress. Limit focus group to six } \\
\text { participants. }\end{array}$ \\
\hline Cognitive impairment & $\begin{array}{l}\text { Slowed thought process. Difficulty in } \\
\text { storing and retrieving information. }\end{array}$ & $\begin{array}{l}\text { Prompts and cues to assist retrieval. Simple } \\
\text { questions. Consider involving caregivers. }\end{array}$ \\
\hline $\begin{array}{l}\text { Speech impairment, for } \\
\text { example, dysphasia and } \\
\text { aphasia }\end{array}$ & $\begin{array}{l}\text { Impaired language skills associated with } \\
\text { processing and understanding. }\end{array}$ & $\begin{array}{l}\text { Allow participants adequate time to express } \\
\text { themselves. Consider non-verbal forms of } \\
\text { communication. }\end{array}$ \\
\hline Communication & $\begin{array}{l}\text { Difficulty in assimilating information to } \\
\text { form an appropriate response. }\end{array}$ & $\begin{array}{l}\text { Simplify questions. Allow time to form a response. } \\
\text { Speak in simple sentences. Limit the number of } \\
\text { participants in the group. }\end{array}$ \\
\hline
\end{tabular}

resume at a later time or date. Although this may be time consuming, it respects participants' autonomy and should contribute towards a greater quality of data. Other researchers working with movement disorder patients have conducted focus groups over a number of sessions. ${ }^{17}$

Considerations should also be made towards restricted physical mobility. Disabled access should always be guaranteed, and venues that are familiar to participants should be chosen wherever possible. Online focus groups might be helpful for some participants. Reflecting on the focus group environment before, during and after data collection also aids researchers' reflexivity, shaping future methodological research considerations. We would recommend involving researchers who were present during data collection in the transcription and analysis processes as this counters any audio-recording issues encountered while also improving researcher reflexivity and the quality of data analysis. ${ }^{10}$

Finally, in research involving multiple human subjects, especially where behavioural and psychiatric changes may manifest themselves, consideration should also be given to handling safeguarding issues should they arise. In our research, we have found the use of vignettes to be a helpful strategy that allows participants to discuss their views without feeling pressured to disclose personal experiences. ${ }^{10}$ Involving clinicians and caregivers in the research process allows these issues to be investigated and managed if necessary. If distress is experienced by a participant before or after a focus group, follow-up by healthcare professionals may also be appropriate. Researchers also have a duty to monitor their own welfare when conducting focus group on sensitive topics or with vulnerable populations. We found that reflexivity or debriefing with other members of the research team preserves wellbeing and can aid data analysis. ${ }^{10}$

Table 2 summarises some of the methodological challenges and recommendations when conducting focus group participants in neurodegenerative disease.

\section{CONCLUSION}

Focus groups are a useful method of qualitative data collection, but their use within neurodegenerative populations is not without problems. Despite these issues, we believe that these patient populations have much to offer researchers and that their contributions should be included. This short report provides advice to researchers on the issues to be mindful of and offers recommendations to improve participation of this vulnerable population in focus group research.

Correction notice This article has been corrected since it was first published. The funding section has been updated.

Contributors FW, AJ and PJ conceived the idea of the communication. VS and MB contributed to the ideas within the communication. AJ drafted the work. MB, PJ, VS and FW critically revised it for intellectual content. All authors gave final approval of the version to be published. All authors agree to be accountable for all aspects of the work in ensuring that questions related to the accuracy or integrity of any part of the work are appropriately investigated and resolved.

Funding This research was supported by funding from Alzheimer's Society, Secretary of State for Health and Social Care, Health and Care Research Wales, 
Public Health Agency Northern Ireland as part of the JPND funding call in to Health and Social Care (2019). The Centre for Trials Research receives funding from Health and Care Research Wales and Cancer Research UK.

Competing interests None declared.

Patient consent for publication Not required.

Provenance and peer review Not commissioned; externally peer reviewed.

Open access This is an open access article distributed in accordance with the Creative Commons Attribution Non Commercial (CC BY-NC 4.0) license, which permits others to distribute, remix, adapt, build upon this work non-commercially, and license their derivative works on different terms, provided the original work is properly cited, appropriate credit is given, any changes made indicated, and the use is non-commercial. See: http://creativecommons.org/licenses/by-nc/4.0/.

\section{ORCID iDs}

Monica Busse http://orcid.org/0000-0002-5331-5909

Victoria Shepherd http://orcid.org/0000-0002-7687-0817

Fiona Wood http://orcid.org/0000-0001-7397-4074

\section{REFERENCES}

1 Thordardottir B, Nilsson $\mathrm{MH}$, Iwarsson S, et al. "You plan, but you never know"-participation among people with different levels of severity of Parkinson's disease. Disabil Rehabil 2014;36:2216-24.

2 Shepherd V. Research involving adults lacking capacity to consent the impact of research regulation on 'evidence biased' medicine. BMC Med Ethics 2016;17:55.

3 Span M, Hettinga M, Groen-van de Ven L, et al. Involving people with dementia in developing an interactive web tool for shared decisionmaking: experiences with a participatory design approach. Disabil Rehabil 2018;40:1410-20.

4 Gehlert S, Mozersky J. Seeing beyond the margins: challenges to informed inclusion of vulnerable populations in research. $J$ Law Med Ethics 2018;46:30-43.
5 Corrigan O. Empty ethics: the problem with informed consent. Sociol Health IIIn 2003;25:768-92.

6 HMSO, London. Mental capacity act: code of practice 2005, 2005.

7 Hamana K, Quinn L, Gambling T, et al. An exploration of physical activity experiences throughout the Huntington's disease journey: supporting development of theoretically underpinned complex interventions. Disabil Rehabil 2019:1-11.

8 Shepherd V, Hood K, Sheehan M, et al. 'It's a tough decision': a qualitative study of proxy decision-making for research involving adults who lack capacity to consent in UK. Age Ageing 2019;48:903-9.

9 Sim J, Waterfield J. Focus group methodology: some ethical challenges. Qual Quant 2019;53:3003-22.

10 Davies F, Edwards A, Brain K, et al. 'You are just left to get on with it': qualitative study of patient and carer experiences of the transition to secondary progressive multiple sclerosis. BMJ Open 2015;5:e007674.

11 Ladonna K, Ravenek M. Challenges and strategies for conducting qualitative research with persons diagnosed with rare movement disorders. Qual Rep 2014;19:1-18.

12 Eddy CM, Parkinson EG, Rickards HE. Changes in mental state and behaviour in Huntington's disease. Lancet Psychiatry 2016:3:1079-86.

13 Miller T, Boulton M. Changing constructions of informed consent: qualitative research and complex social worlds. Soc Sci Med 2007;65:2199-211.

14 Feys P, Gijbels D, Romberg A, et al. Effect of time of day on walking capacity and self-reported fatigue in persons with multiple sclerosis: a multi-center trial. Mult Scler 2012;18:351-7.

15 Paterson B, Scott-Findlay S. Critical issues in interviewing people with traumatic brain injury. Qual Health Res 2002;12:399-409.

16 Harris R, Dyson E. Recruitment of frail older people to research: lessons learnt through experience. J Adv Nurs 2001;36:643-51.

17 Ivanoff SD, Hultberg J. Understanding the multiple realities of everyday life: basic assumptions in focus-group methodology. Scand J Occup Ther 2006;13:125-32. 